JURNAL JASATEC

Journal Of Students of Automotive, Electronic and Computer e-print: 2808-6627

https://jurnal.politeknik-kebumen.ac.id/index.php/jasatec

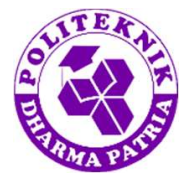

\title{
PERANCANGAN SISTEM INFORMASI PENJUALAN BOX DAN TEMPAT SESERAHAN DI "F" PRODUCTION SRUWENG BERBASIS WEB DENGAN FRAMEWORK CODEIGNITER
}

\author{
Aldi Zubaidi ${ }^{1}$, Riswondo Mahardiko ${ }^{2}$, Fitriani Dwi Ratna Sari ${ }^{3}$ \\ 1,2,3,Diploma Teknik Elektronika, Politeknik Piksi Ganesha Indonesia, Indoneia, 54311
}

: aldisubaidi83@gmail.com

: https://10.37339/jasatec.v\%vi\%i.759

Diterima : 05/10/2021 | Direvisi : 05/10/2021 | Disetujui : 17/10/2021

\section{Diterbitkan oleh Politeknik Dharma Patria Kebumen}

\begin{abstract}
Abstrak :
Toko F Production bergerak pada bidang kerajinan tangan seperti seserahan dan box, memiliki pelanggan cukup banyak sehingga diperlukan sistem informasi penjualan berbasis website untuk memudahkan para pelanggan membeli produk di Toko $\mathrm{F}$ Production tanpa harus mengunjungi toko secara langsung. Karena itulah Toko F membutuhkan sebauh sistem informasi penjualan online yang berbasis website yang nantinya akan terintegrasi untuk mengelola segala masalah yang terjadi pada toko F. Sistem yang dihasilkan nantinya akan dikembangkan dengan metode SDLC, bahasa pemrograman PHP, dan dengan database MySQL.
\end{abstract}

Kata Kunci : Transaksi, Penjualan, WEB

\begin{abstract}
:
The F Production shop is enganged in handicrafts such as offerings and boxes, has quite a lot of customers so a website-based sales information system is needed to make it easier for customers to buy products at the F Production Store without having to visit the store directly. That's why Store $F$ requires an online sales information system based on a website which will later be integrated to manage all problems that occur in store $F$. The resulting system will be developed using the SDLC method, PHP Programming language, and with a MYSQL database.
\end{abstract}

Keywords : Transaction, Sale, WEB 


\section{PENDAhUluan}

"Inter Connection Networking" (Internet) adalah jaringan komputer yang menghubungkan antara jaringan secara global, internet dapat juga disebut jaringan dalam suatu satu jaringan yang luas [1]. Internet juga menggunakan protocol komunikasi yaitu TCP/IP (Transmission Control Protocol/ Internet Protocol). Ecommerce didefinisikan sebagai transaksi perdagangan yang dimungkinkan secara digital antara organisasi dengan organisasi atau dengan individual serta antar individual dengan individual. Toko $\mathrm{F}$ adalah suatu usaha yang bergerak dibidang penjualan berbagai macam Box dan Seserahan. Masalah yang dihadapi oleh toko $\mathrm{F}$ adalah sistem penjualan yang dilakukan secara offline, dimana konsumen harus datang langsung ke toko jika ingin membeli barang. Kurang luasnya jangkauan promosi yang digunakan oleh toko $\mathrm{F}$ masih menggunakan media spanduk didepan toko. Penyimpanan data dan pencetakan laporan masih menggunakan pencatatan kedalam arsip.

Batasan masalah pada penelitian ini meliputi transaksi penjualan berbasis ecommerce, promosi melalui media website, penyimpanan data yang akan disimpan kedalam database sehingga mempermudah ketika akan mencetak laporan. Tujuan penelitian ini adalah menghasilkan sistem informasi penjualan berbasis e-commerce yang nantinya akan dapat membantu dalam pengolahan data, promosi dan transaksi yang dilakukan melalui media website e-commerce.

\section{KAJIAN PUSTAKA}

\subsection{E-Commerce}

E-commerce adalah suatu perangkat teknologi yang dinamis, meliputi aplikasi dan proses bisnis yang menghubungkan suatu perusahaan, konsumen dan suatu komunitas melalui transaksi elektronik, yang menyelenggarakan pertukaran elektronik barang [2].

\subsection{Website}

"Word Wide Web atau Waring Wera Wanua" (WWW) adalah suatu ruang informasi yang dipakai oleh pengenal global yang disebut Pengidentifikasi Sumber Seragam untuk mengenal pasti sumberdaya berguna. WWW sering dianggap sama dengan internet secara keseluruhan, walaupun sebenarnya hanyalah bagian dari internet [3]. 


\subsection{Sistem}

Sistem adalah sekumpulan elemen yang saling terkait atau terpadu yang dimaksudkan untuk mencapai tujuan [4].

\subsection{Informasi}

Informasi adalah data yang diolah menjadi bentuk yang lebih berguna dan lebih berate bagi yang menerimanya [5].

\section{METODE}

Pada metode penelitian terdapat teknik pengumpulan data dan model pengembangan. Adapun teknik pengumpulan data yang akan dibahas dalam penulisan ini sebagai berikut: Pertama observasi dilakukan dengan melakukan pengamatan secara langsung dan mendatangi tempat tentang legiatan-kegiatan pengambilan data mengenai penjualan pada Toko F. metode ini merupakan kegiatan yang direncanakan, melihat langsung, menganalisa, serta mencatat teratur dan sistematik objek yang akan diteliti. Kedua, wawancara dengan melakukan tanya jawab kepada pemilik Toko dan beberapa orang narasumber. Ketiga, studi pustaka dengan mengumpulkan data dari buku-buku yang berkaitan dengan masalah yang akan dibahas untuk mendukung data yang telah didapat. Metode yang digunakan dengan penelitian adalalah model waterfall. Model waterfall adalah model SDLC yang paling sederhana, model ini hanya cocok untuk pengembangan perangkat lunak dengan spesifikasi yang tidak berubahubah [6].

\subsection{Pemodelan UML}

Perancangan sistem dengan menggunakan pemodelan UML (Unified Modelling Language). UML adalah bahasa pemodelan untuk sistem atau peramgkat lunak yang berparadikma (berorientasi objek) [7].

\subsubsection{Use Case Diagram}

Use Case Diagram yang digunakan untuk menggambarkan proses pemesanan dan pembelian produk yang dilakukan oleh konsumen pada Toko F dapat disajikan pada Gambar 1. 


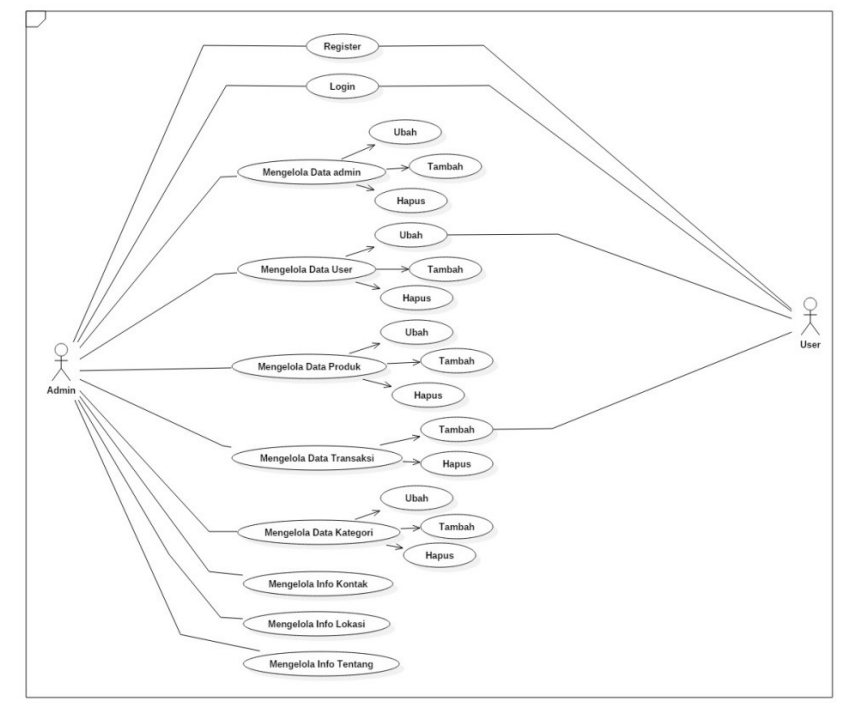

Gambar 1. Use Case Diagram pelanggan order produk.

\subsubsection{Class Diagram}

Class diagram yang digunakan dalam website Toko $\mathrm{F}$, dimana spesifikasi class diagram yang digunakan berikut berdasarkan spesifikasi basis data yang dimiliki oleh website Toko F, dan dapat menggambarkan struktur serta deskripsi class, package dan objek beserta hubungan satu sama lain [8]. Dapat disajikam

\section{Gambar 2.}

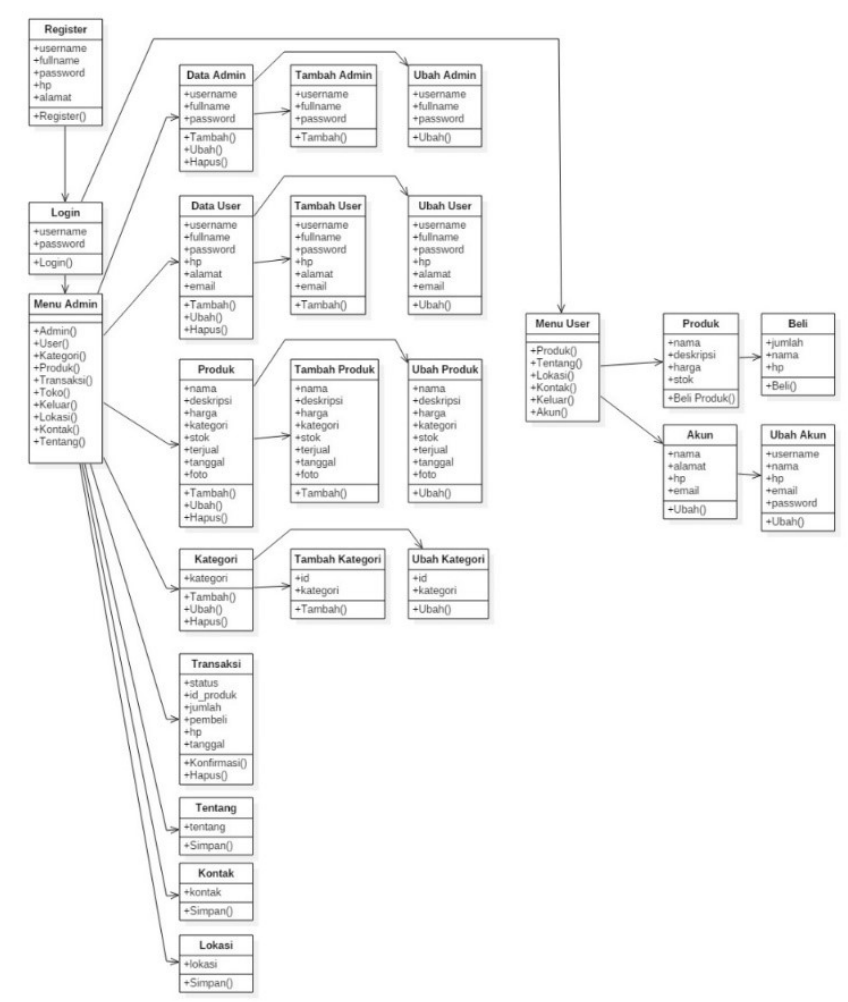

Gambar 2. Class Diagram Toko F 


\subsubsection{Activity Diagram}

Activity Diagram adalah diagram yang menggambarkan sifat dinamis secara alamiah sebuah sistem dalam bentuk model aliran dan control dari aktifitas ke aktifitas lainnya [9]. Activity Diagram menggambarkan berbagai alir aktifitas dalam sistem yang sedang dirancang bagaimana masing-masing alir berawal, decision yang mungkin terjadi, dan bagaimana mereka berakhir. Aliran aktifitas yang dilakukan pengunjung didalam sistem dapat disaksikan pada Gambar 3.

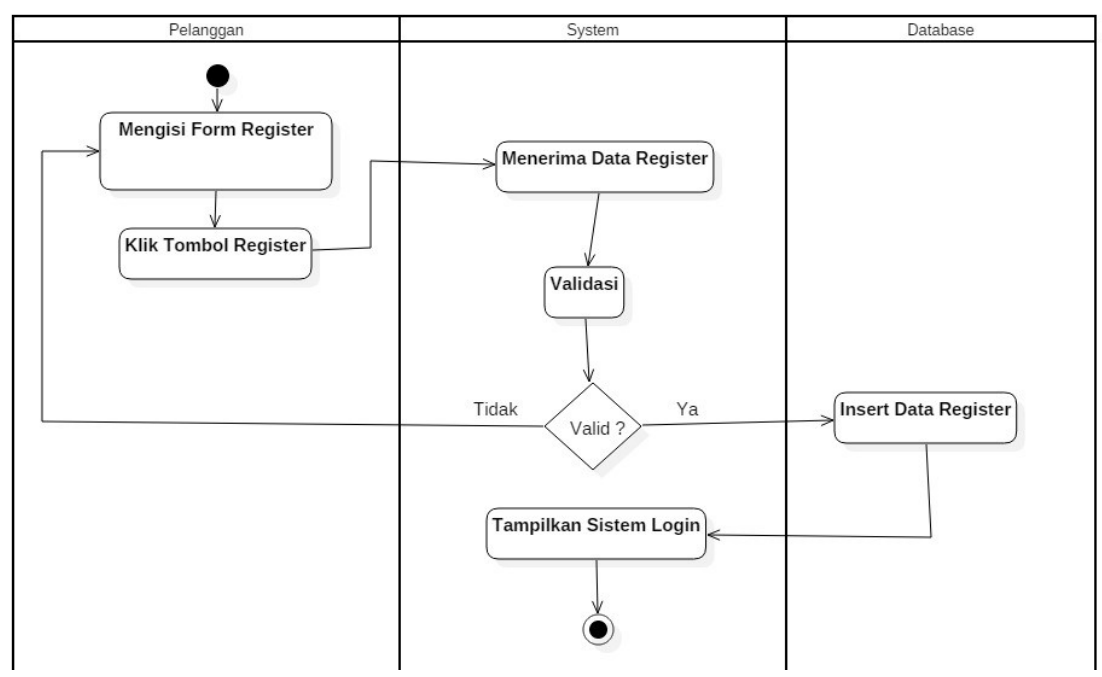

Gambar 3. Activity Diagram Login

Activity Diagram Register adalah proses register akun user. User memilih menu register kemudian sistem menampilkan form register akun. Setelah mengisi semua form pada kolom register, maka akan muncul tombol konfirmasi. Dapat disaksikan pada Gambar 4.

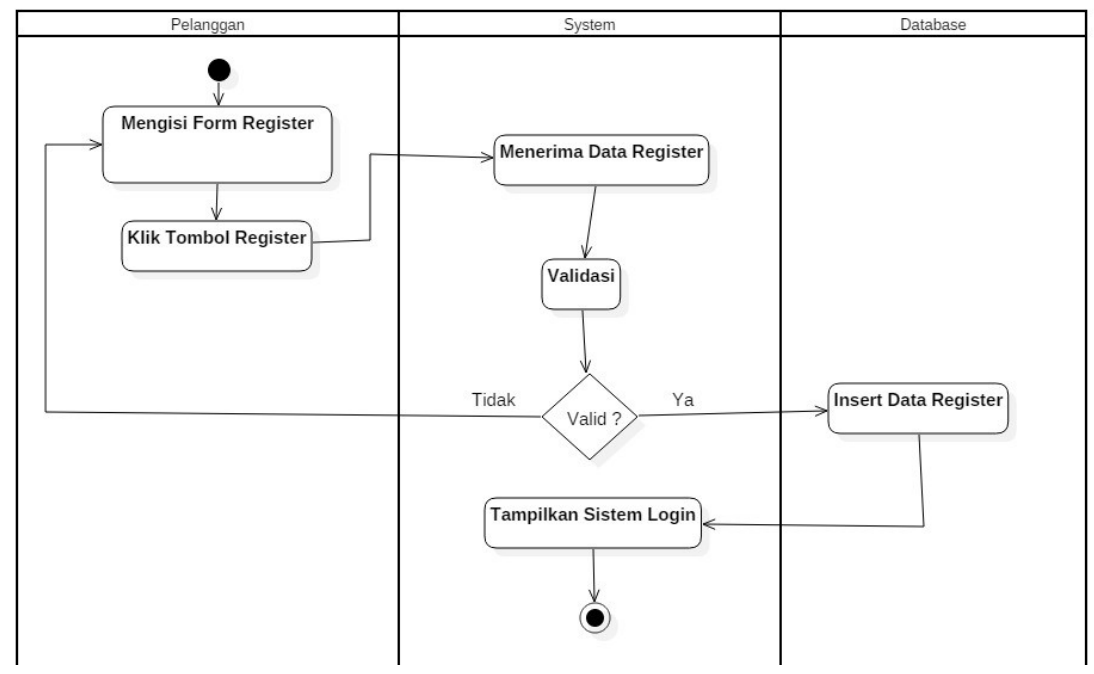

Gambar 4. Activity Diagram Register 


\subsubsection{Sequence Diagram}

Sequence Diagram merupakan interaksi dari objek yang disusun dalam suatu urutan kejadian tertentu dalam suatu proses [10]. Sequence Diagram pada saat melakukan login dapat disaksikan pada Gambar 5.

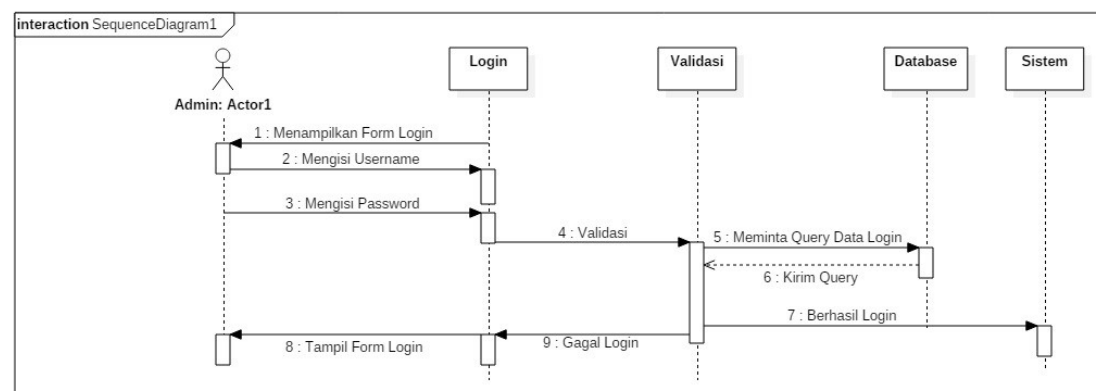

Gambar 5. Sequence Diagram Login

Dalam melakukan kegiatan menambahkan data produk terdiri dari beberapa objek yang dapat digambarkan dengan sequence diagram. Model sequence Diagram dapat disajikan pada Gambar 6.

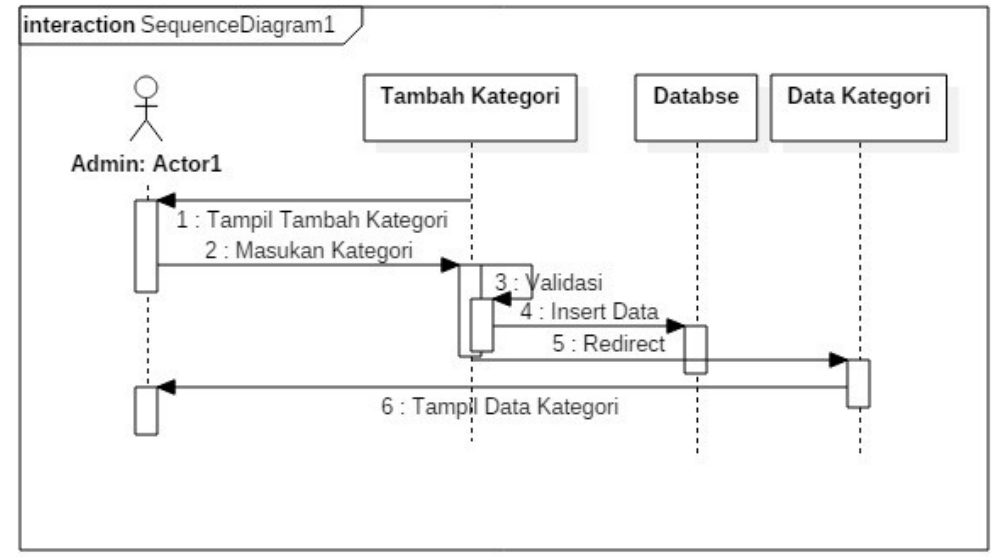

Gambar 6. Sequence Diagram Penambahan Kategori

\section{HASIL DAN PEMBAHASAN}

\subsection{HASIL}

\section{PENGUJIAN SISTEM}

Pengujian sistem merupakan hal penting yang bertujuan untuk memastikan semua fungsi sistem bekerja dengan baik dan untuk menemukan kesalahan atau kekurangan yang terjadi pada sistem yang diuji dengan menggunakan sekala interen dan belum melibatkan operator eksternal.

\section{HASIL PENGUJIAN SISTEM}

Hasil dari pengujian system diperoleh dari table sebagai berikut: 
Tabel 1. Hasil Pengujian sistem

\begin{tabular}{|c|c|c|c|c|c|}
\hline No & Form & $\begin{array}{l}\text { Deskripsi } \\
\text { Pengujian }\end{array}$ & $\begin{array}{l}\text { Skenario } \\
\text { Pengujian }\end{array}$ & Hasil Yang Diuji & Keterangan \\
\hline 1 & Login & $\begin{array}{l}\text { Login } \\
\text { Berhasil }\end{array}$ & $\begin{array}{l}\text { Admin } \\
\text { Memasukan User } \\
\text { Name dan } \\
\text { Password Yang } \\
\text { Benar }\end{array}$ & $\begin{array}{l}\text { Admin berhasil } \\
\text { login dan sukses }\end{array}$ & Sukses \\
\hline 2 & Login & Login Gagal & $\begin{array}{l}\text { Admin } \\
\text { memasukan user } \\
\text { name dan } \\
\text { password salah }\end{array}$ & $\begin{array}{l}\text { Admin gagal } \\
\text { login }\end{array}$ & Sukses \\
\hline 3 & $\begin{array}{l}\text { Tambah } \\
\text { user }\end{array}$ & $\begin{array}{l}\text { Pengujian } \\
\text { menu } \\
\text { tambah user }\end{array}$ & $\begin{array}{l}\text { Klik tambah user } \\
\text { kemudian isi data } \\
\text { diri }\end{array}$ & $\begin{array}{l}\text { Berhasil } \\
\text { menambah user }\end{array}$ & Sukses \\
\hline 4 & $\begin{array}{l}\text { Tambah } \\
\text { barang }\end{array}$ & $\begin{array}{l}\text { Pengujian } \\
\text { mwnu } \\
\text { tambah } \\
\text { barang }\end{array}$ & $\begin{array}{l}\text { Klik menu } \\
\text { tambah barang }\end{array}$ & $\begin{array}{l}\text { Berhasil } \\
\text { menambah } \\
\text { barang }\end{array}$ & Sukses \\
\hline 5 & $\begin{array}{l}\text { Data } \\
\text { barang }\end{array}$ & $\begin{array}{l}\text { Pengujian } \\
\text { delete data } \\
\text { barang oleh } \\
\text { admin } \\
\end{array}$ & $\begin{array}{l}\text { Klik data barang } \\
\text { kemudian delete }\end{array}$ & $\begin{array}{l}\text { Berhasil } \\
\text { menghapus data } \\
\text { barang }\end{array}$ & Sukses \\
\hline 6 & Edit profil & $\begin{array}{l}\text { Pengujian } \\
\text { edit profil }\end{array}$ & $\begin{array}{l}\text { Klik bagian profil } \\
\text { kemudian } \\
\text { masukan data } \\
\text { profil sesuai } \\
\text { kebutuhan } \\
\end{array}$ & $\begin{array}{l}\text { Berhasil } \\
\text { merubah profil }\end{array}$ & Sukses \\
\hline 7 & $\begin{array}{l}\text { Edit } \\
\text { kontak }\end{array}$ & $\begin{array}{l}\text { Pengujian } \\
\text { menu edit } \\
\text { kontak }\end{array}$ & $\begin{array}{l}\text { Klik bagian menu } \\
\text { kontak kemudian } \\
\text { masukan kontak }\end{array}$ & $\begin{array}{l}\text { Berhasil } \\
\text { memasukan data } \\
\text { kontak }\end{array}$ & Sukses \\
\hline 8 & $\begin{array}{l}\text { Edit } \\
\text { tentang }\end{array}$ & $\begin{array}{l}\text { Pengujian } \\
\text { menu } \\
\text { tentang }\end{array}$ & $\begin{array}{l}\text { Klik bagian menu } \\
\text { tentang } \\
\text { kemudian isi } \\
\text { tentang }\end{array}$ & $\begin{array}{l}\text { Berhasil } \\
\text { memasukan data } \\
\text { tentang }\end{array}$ & Sukses \\
\hline 9 & Edit lokasi & $\begin{array}{l}\text { Pengujian } \\
\text { menu lokasi }\end{array}$ & $\begin{array}{l}\text { Klik bagian menu } \\
\text { lokasi kemudian } \\
\text { isi data lokasi }\end{array}$ & $\begin{array}{l}\text { Berhasil } \\
\text { memasukan data } \\
\text { lokasi }\end{array}$ & Sukses \\
\hline
\end{tabular}

Tampilan Login dapat disajikan pada Gambar 7.

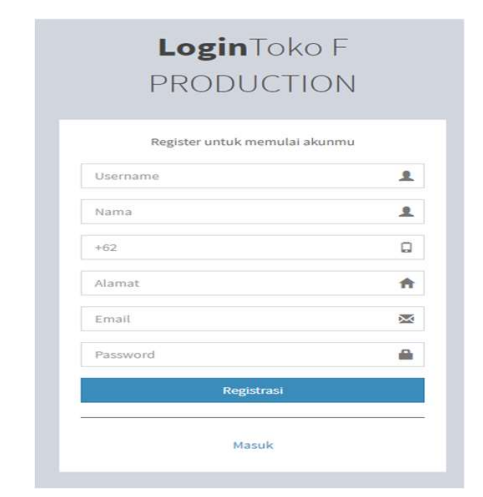

Gambar 7. Halaman Login 
Tampilan daftar produk dapat disajikan pada Gambar 8.

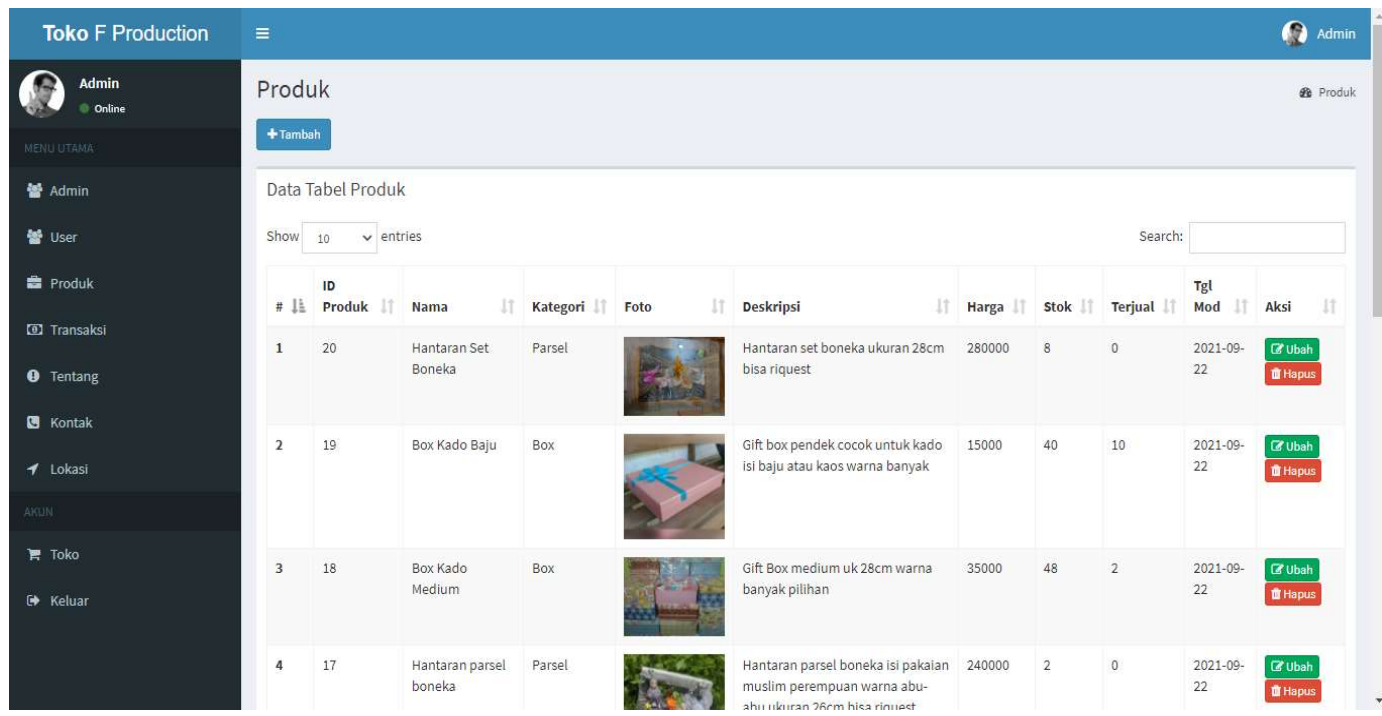

Gambar 8. Halaman Produk

Tampilan pemesanan barang dapat disajikan pada Gambar 9.

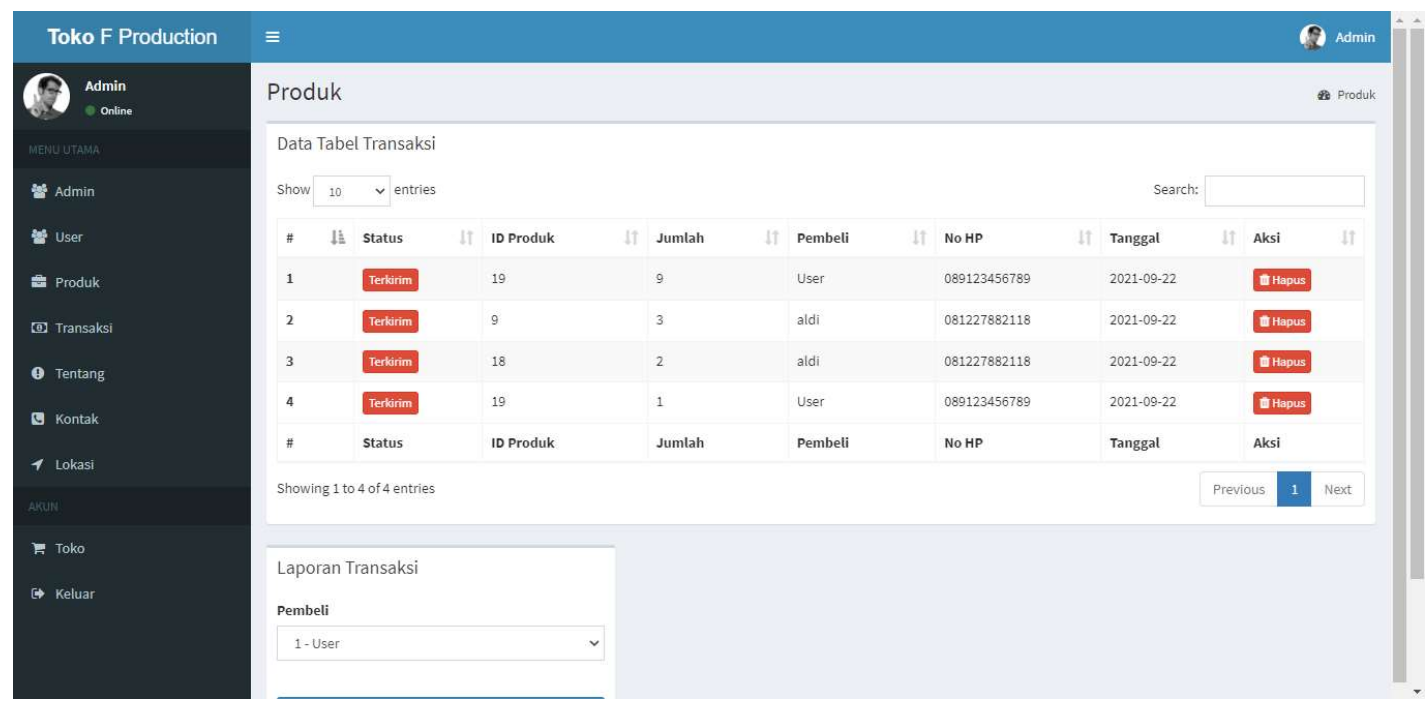

Gambar 9. Pemesanan Barang

\subsection{PEMBAHASAN}

Desain system informasi penjualan berbasis web, dibuat untuk memberikan informasi dan membantu dalam proses kegiatan transaksi serta pembuatan laporan para konsumen mendapat kemudahan dengan melihat detail informasi barang dengan mengakses website tersebut dan kemudahan bagi pihak penjual yaitu dapat mengecek kegiatan transaksi pemesanan ataupun penjualan terkini. Dengan system ini diharapkan dapat membantu pemilik dalam mengambil keputusan dengan dukungan data yang tersedia. Team penguji adalah dosen pembiimbing yaitu Fitri Dwi Ratna Sari,ST.,MM 


\section{KESIMPULAN}

Berdasarkan penelitian yang telah dilakukan, maka dapat diambil kesimpulan hasil dari penelitian, sebagai berikut:

a. Website dapat digunakan sebagai media promosi yang menginformasikan produk-produk terbaru dan berkualitas sehingga dapat meningkatkan grafik penjualan pada Toko $\mathrm{F}$.

b. Dengan dibangunnya sistem informasi maka semua pengolahan data dilakukan secara komputerisasi yang dilakukan oleh sistem untuk memperkecil kesalahan

c. Dengan adanya sistem informasi penjualan barang berbasis website dapat mempermudah pelanggan dalam melakukan pembelian barang pada Toko $\mathrm{F}$ lebih efesien dalam hal waktu dan juga jarak.

\section{REFERENSI}

[1] F.A. Sibero, WEB Programming Power Pack. Yogyakarta: Mediakom, 2013.

[2] H.T. Sihotang, "Sistem pakar untuk mendiagnosa penyakit pada tanaman jagung dengan metode bayes, "J. Inform. Pelita Nusant., Vol.3, No.1, 2018.

[3] M. Sandi, bikin website dengan aplikasi-aplikasi gratis. Yogyakarta: Mediakom, 2014.

[4] Jogiyanto. (2005). "Analisis dan Desain Sistem Informasi". Yogyakarta: ANDI.

[5] Kadir, A. (2014). "Pengenal Sistem Informasi". Yogyakarta: ANDI.

[6] R. A. M. S. Sukamto, "Rekayasa Perangkat Lunak Terstruktur dan Beroroentasi Objek". Bandung: Informatika Bandung, 2013.

[7] Nugroho. Adi, "Rekayasa Perangkat Lunak Menggunakan UML dan Java". Yogyakarta: Andi Offset, 2009.

[8] M. Novianta, E. Setyaningsih, "Sistem Informasi Monitoring Kereta Api". Jurnal Momentum Vol 17 no. 2, 2015

[9] Haviluddin, "Memahami Penggunaan UML (Unified Modelling Language)". Jurnal Informatika Mulawarman Vol 6 no. 1, 2011.

[10] Rice Novita, "Sistem Infomasi Penjualan Pupuk Berbasis E-Commerce", Jurnal TEKNOIF, Vol. 3 no. 2, 2015 